\title{
Persistence of ozone anomalies in the Arctic stratospheric vortex in autumn
}

\author{
D. Blessmann, I. Wohltmann, R. Lehmann, and M. Rex \\ Alfred Wegener Institute for Polar and Marine Research, Potsdam, Germany \\ Correspondence to: I. Wohltmann (ingo.wohltmann@awi.de) \\ Received: 10 May 2011 - Published in Atmos. Chem. Phys. Discuss.: 8 December 2011 \\ Revised: 9 May 2012 - Accepted: 11 May 2012 - Published: 1 June 2012
}

\begin{abstract}
Dynamical processes during the formation phase of the Arctic stratospheric vortex in autumn (from September to December) can introduce considerable interannual variability in the amount of ozone that is incorporated into the vortex. Chemistry in autumn tends to remove part of this variability because ozone relaxes towards equilibrium. As a quantitative measure of how important dynamical variability during vortex formation is for the winter ozone abundances above the Arctic we analyze which fraction of an ozone anomaly induced during vortex formation persists until early winter (3 January). The work is based on the Lagrangian Chemistry Transport Model ATLAS. In a case study, model runs for the winter 1999-2000 are used to assess the fate of an ozone anomaly artificially introduced during the vortex formation phase on 16 September. In addition, runs with reduced resolution explore the sensitivity of the results to interannual changes in transport, mixing, temperatures and $\mathrm{NO}_{\mathrm{x}}$. The runs provide information about the persistence of the induced ozone anomaly as a function of time, potential temperature and latitude. The induced ozone anomaly survives longer inside the polar vortex than outside the vortex. Half of the initial perturbation survives until 3 January at $550 \mathrm{~K}$ inside the polar vortex, with a rapid fall off towards higher levels, mainly due to $\mathrm{NO}_{\mathrm{x}}$ induced chemistry. Above $750 \mathrm{~K}$ the signal falls to values below $0.5 \%$. Hence, dynamically induced ozone variability from the early vortex formation phase cannot significantly contribute to early winter variability above $750 \mathrm{~K}$. At lower levels increasingly larger fractions of the initial perturbation survive, reaching $90 \%$ at $450 \mathrm{~K}$. In this vertical range dynamical processes during the vortex formation phase are crucial for the ozone abundance in early winter.
\end{abstract}

\section{Introduction}

While stratospheric processes in Arctic winter and spring were extensively studied in the last decades in response to the issue of anthropogenic ozone depletion (e.g. WMO, 2011), stratospheric ozone chemistry and dynamics in autumn have received relatively little attention so far (e.g. Fahey and Ravishankara, 1999; Kawa et al., 2003; Tilmes et al., 2006), even though they set the initial conditions for the winter season.

The ozone layer in the Arctic stratosphere usually shows a large interannual variability. However, at the beginning of autumn in September, just before the polar vortex forms, the interannual variability in the ozone abundance is low throughout the Arctic stratosphere, since the variability induced earlier in the year slowly decays to the chemically determined equilibrium by the end of the summer (Fioletov and Shepherd, 2003; Kiesewetter et al., 2010).

Here we focus on the variability which is then newly introduced by transport and chemical processes during the formation of the polar vortex in autumn (in the months from September to December). Typically, ozone profiles in November show mixing ratios of about $3 \mathrm{ppm}$ that are relatively constant with altitude from $500 \mathrm{~K}$ to $800 \mathrm{~K}$, but with an interannual variability of about $10 \%$ (Kawa et al., 2003, 2005). This variability of polar ozone is related to wave activity and mixing from lower latitudes (Rosenfield and Schoeberl, 2001; Kawa et al., 2003). We are going to investigate on which timescales variability is conserved or decays due to chemical processes in the months up to early winter (3 January).

The Lagrangian Chemistry and Transport Model ATLAS is used in a case study for the winter 1999-2000 to quantify how long an initial perturbation of ozone survives the 
chemical processing and at which altitudes and latitudes it potentially contributes to the early winter variability of ozone. Since the photochemical lifetime of ozone is a pronounced function of potential temperature, latitude and season, results will strongly depend on these parameters. As the solar insolation is the same in every year, the results will be relatively insensitive to the particular year chosen. Runs with reduced resolution for the years 2005/2006 to 2010/2011 show that interannual changes in transport, mixing, temperature or $\mathrm{NO}_{\mathrm{x}}$ are of secondary importance for the lifetime of the signal.

In the Arctic stratosphere the circulation in summer is characterized by slow easterly motion, preventing the vertical propagation of planetary scale waves from their source regions in the troposphere into the stratosphere (Charney and Drazin, 1961). But after autumnal equinox thermal emission leads to subsidence of air over the polar region and to a reversal of the circulation, westerly winds and eventually to the formation of the polar vortex (Schoeberl and Hartmann, 1991; Kawa et al., 2003). Then the strong westerlies forming the polar vortex again prevent the vertical propagation of planetary waves and suppress meridional mixing. However, in the period of weak westerlies during vortex formation waves can propagate freely into the stratosphere and meridional mixing can be strong. The degree to which these waves transport low latitude air and ozone into the Arctic depends on the level of wave activity in the troposphere during this brief sensitive period, which typically lasts from the middle of September to the middle of November. Since chemical processes during summer lead to a strong meridional gradient in the ozone field, the variable degree of meridional mixing introduces variability in the ozone abundance at high latitudes that is then enclosed by the polar vortex.

The variability in ozone levels introduced by this or any other potential process during vortex formation tends to decay during the following weeks and months due to relaxation of ozone towards its chemically determined equilibrium, mainly by $\mathrm{NO}_{\mathrm{x}}$ chemistry (Fahey and Ravishankara, 1999; Fahey et al., 2000). Only the fraction of variability that survives the chemical processing in autumn can contribute to the interannual variability of ozone inside the polar vortex in early winter, unless there is some feedback on dynamics and transport. The chemical processing and relaxation towards equilibrium occurs in competition with the decrease in solar insolation which eventually suppresses further chemical conversion of ozone such that the degree of variability remaining at that time is conserved.

How this early winter ozone variability might be related to total ozone later in the winter was investigated by Kawa et al. (2005) and Sinnhuber et al. (2006). They found a significant correlation between the early winter (November) ozone abundance and late winter (March) total ozone. However, the causes of this correlation remain unclear and are not in the scope of this study.

\section{Model}

\subsection{Model description}

ATLAS is a global Chemistry and Transport Model with detailed stratospheric chemistry and a Langrangian (trajectorybased) transport and mixing scheme (Wohltmann and Rex, 2009; Wohltmann et al., 2010). Lagrangian models have several advantages over conventional Eulerian models, in particular no spurious numerical diffusion and a more realistic transport of chemical species (e.g. Wohltmann and Rex, 2009).

The chemistry module comprises 46 active species and 171 reactions. These include 42 photolysis reactions, 122 gas phase reactions and 7 heterogeneous reactions on liquid aerosols, nitric acid trihydrate clouds and ice clouds. The parameterizations of Carslaw et al. (1995) are used for the liquid particles. The relevant rate constants are taken from the recommendations in the JPL 2006 catalogue and its 2009 update (Sander et al., 2006, 2009). Further details and a validation of the model can be found in Wohltmann and Rex (2009) and Wohltmann et al. (2010).

\subsection{Model runs}

This study is based on two model runs, a reference run with an unmodified ozone field and a perturbation run. Both runs simulate the period 1 July 1999 to 31 March 2000. In the perturbation run the ozone field is artificially increased by $30 \%$ on 16 September 1999. The number is chosen based on the observed variability of ozone as deduced from ozone sondes. The perturbation simulates the effect of interannual variability in high latitude ozone during vortex formation. Obviously such perturbations survive longer in regions of longer ozone lifetimes, i.e. at higher latitudes and lower potential temperatures.

Since it is the relative change in ozone (relative to the initial perturbation) which is of interest here, we assume that the sensitivity of the relative change to the magnitude of the initial perturbation is small. Simplified box model runs performed by us with other perturbations than $30 \%$ support this hypothesis.

Chemical species are initialized on 1 August, after a spin up period for the transport scheme of the model in July. The initialization of water vapor $\left(\mathrm{H}_{2} \mathrm{O}\right)$, methane $\left(\mathrm{CH}_{4}\right)$, ozone $\left(\mathrm{O}_{3}\right)$, nitrogen dioxide $\left(\mathrm{NO}_{2}\right.$, as a proxy for $\left.\mathrm{NO}_{\mathrm{x}}\right)$ and hydrochloric acid $(\mathrm{HCl})$ is based on bi-monthly means of $\mathrm{Au}-$ gust and September 1999 of measurements by the HALOE solar occultation instrument onboard the Upper Atmosphere Research Satellite (UARS) as a function of equivalent latitude and pressure (Grooß and Russell III, 2005). Equivalent latitude is defined as the latitude an area enclosed by a potential vorticity contour would have, if it would be circular and centered at the pole (e.g. Butchart and Remsberg, 1986). Nitric acid $\left(\mathrm{HNO}_{3}\right)$ and carbon monoxide $(\mathrm{CO})$ are initialized 

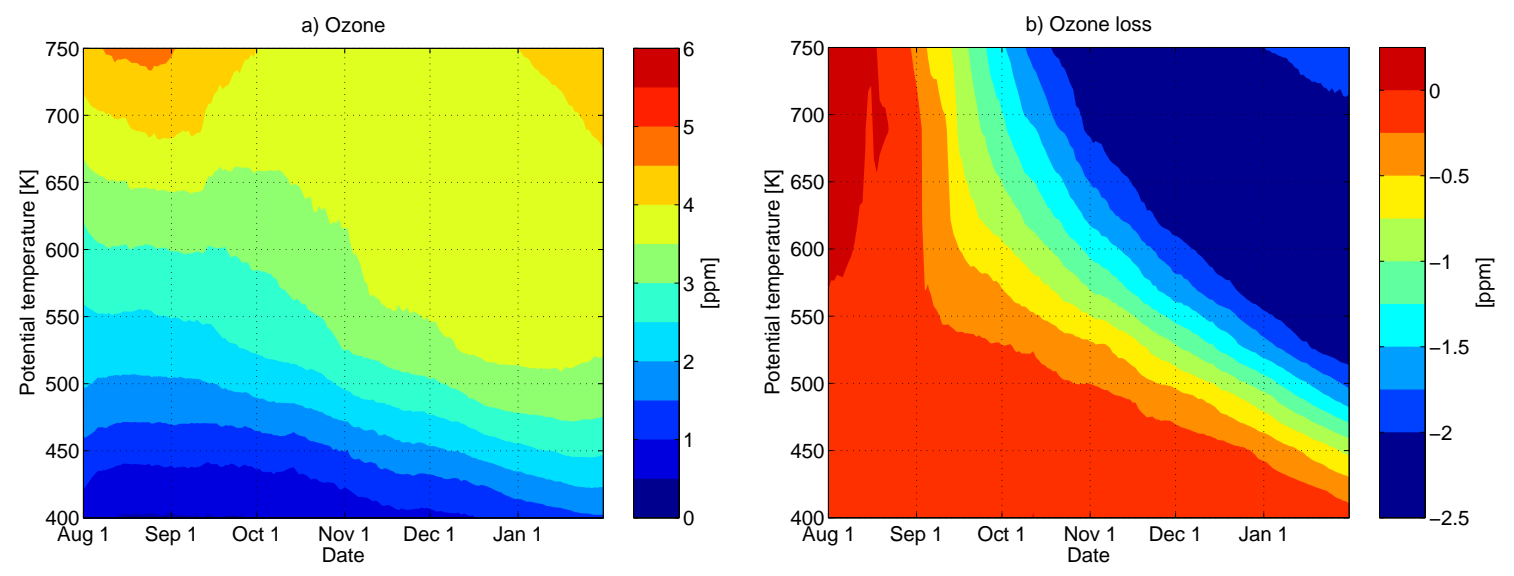

Fig. 1. (a) Mean ozone mixing ratios as a function of potential temperature and time, averaged over equivalent latitudes greater than $65^{\circ} \mathrm{N}$. (b) Same for the ozone loss as the difference between the passive ozone tracer and modeled ozone.

with a climatology based on data of the ACE FTS interferometer onboard the SCISAT-1 satellite (Bernath et al., 2005). $\mathrm{N}_{2} \mathrm{O}$ is deduced from a $\mathrm{N}_{2} \mathrm{O}-\mathrm{CH}_{4}$ tracer-tracer relationship derived from ER-2 and Triple balloon data (Grooß et al., 2002). $\mathrm{ClONO}_{2}$ is initialized as the difference between $\mathrm{HCl}$ and $\mathrm{Cl}_{\mathrm{y}} \cdot \mathrm{Cl}_{\mathrm{y}}$ is calculated from a $\mathrm{Cl}_{\mathrm{y}}-\mathrm{CH}_{4}$ relationship from ER-2 and Triple balloon data (Grooß et al., 2002). The initial $\mathrm{Br}_{\mathrm{y}}$ is derived from a $\mathrm{Br}_{\mathrm{y}}-\mathrm{CH}_{4}$ relationship (Grooß et al., 2002) and assumed to be in the form of $\mathrm{BrONO}_{2}$. Additionally, in order to achieve agreement with Differential Optical Absorption Spectroscopy (DOAS) measurements of $\mathrm{BrO}$ (Dorf et al., 2008), $\mathrm{Br}_{\mathrm{y}}$ is scaled by a constant factor to give maximum values of 19.9 ppt. CFCs and related species are initialized as in Wohltmann et al. (2010).

We have based our model runs on ERA Interim reanalysis data (Dee et al., 2011) from the European Centre for Medium Range Weather Forecasts (ECMWF) with a horizontal resolution of $2^{\circ} \times 2^{\circ}$. The meteorological fields are given every $6 \mathrm{~h}$. The trajectories are calculated with a $30 \mathrm{~min}$ time step. The model runs are performed with an effective approximate horizontal resolution of $200 \mathrm{~km}$ in a vertical domain from $350 \mathrm{~K}$ to $1900 \mathrm{~K}$. The Lyapunov exponent, which adjusts the mixing strength, is set to $4 \mathrm{day}^{-1}$ (Wohltmann and Rex, 2009) and the mixing time step to $12 \mathrm{~h}$. We use a hybrid coordinate as vertical coordinate, which is to a good approximation a potential temperature coordinate in the stratosphere. The vertical motion is driven by diabatic heating rates (clear sky) from ERA Interim.

A passive ozone tracer is initialized on 1 August identical to the ozone field of the model. In the following, this tracer is only affected by transport and mixing and not by chemistry. The difference between the modeled ozone and the passive ozone tracer is a measure for the chemically induced ozone change.

\section{Results}

In Fig. 1, we show results of the unperturbed run as a reference. Figure 1a shows the time evolution of ozone and Fig. 1b the chemical loss of ozone as the difference between the passive tracer and modeled ozone, both averaged over $65-90^{\circ} \mathrm{N}$ equivalent latitude. Generally, ozone mixing ratios increase with potential temperature and ozone isopleths subside during winter, leading to an increase of ozone on fixed potential temperature levels in the lower stratosphere below approximately $550 \mathrm{~K}$ (Fig. 1a). In the middle stratosphere the increase in ozone due to subsidence is modified by chemical loss. Air reduced in ozone propagates downward to the lower stratosphere during autumn (Fig. 1b). This explains the observed decrease in ozone above $700 \mathrm{~K}$ during autumn (Fig. 1a) and also leads to a flattening of the vertical gradient between 550 and $750 \mathrm{~K}$ (as also observed by Kawa et al., 2003).

The chemically induced decrease in ozone at these altitudes in September and October is due to the fact that the equilibrium concentration of ozone drops while solar zenith angles increase in autumn. Ozone concentrations in late summer are close to chemical equilibrium, which results from the balance of ozone production (governed by $\mathrm{O}_{2}$ photolysis) and loss (Fahey and Ravishankara, 1999; Fahey et al., 2000). At these altitudes and under polar summer conditions, the loss is dominated by chemistry involving $\mathrm{NO}_{\mathrm{x}}$ species, which are present at high concentrations since high amounts of $\mathrm{NO}_{\mathrm{y}}$ subsided into the polar middle stratosphere during the preceding winter and these are efficiently converted into $\mathrm{NO}_{\mathrm{x}}$ during polar day in summer (Farman et al., 1985; Fahey and Ravishankara, 1999).

The ozone production via $\mathrm{O}_{2}$ photolysis requires the presence of UV radiation $(\lambda<240 \mathrm{~nm})$ while the efficiency of $\mathrm{NO}_{\mathrm{x}}$ catalysed ozone loss is governed by the photolysis frequency of $\mathrm{O}_{3}$, which photolyses in visible light $(\lambda<1180 \mathrm{~nm})$. When solar zenith angles increase in autumn 


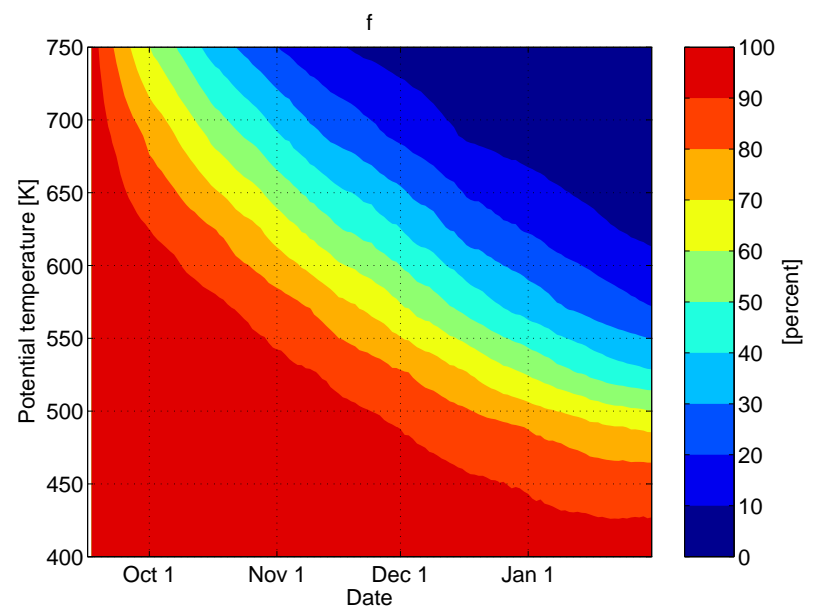

Fig. 2. Surviving fraction of an artificial ozone perturbation on 16 September 1999 according to Eq. (1) as a function of potential temperature and time, averaged over equivalent latitudes greater than $65^{\circ} \mathrm{N}$.

the availability of UV light drops much faster than that of visible light, since the light path through the ozone layer increases, which absorbs UV light but does not attenuate visible light much (Kawa et al., 2003). Hence ozone production drops faster than ozone loss and the equilibrium concentration of ozone decreases. At the same time the lifetime of ozone increases. At lower altitudes, the rate of change of the equilibrium value of ozone is faster than the rate of change (i.e. reciprocal lifetime) of ozone. Hence, the ozone concentrations relax slowly towards the new equilibrium.

Figure 2 is based on the difference between the reference run and the perturbation run and shows the fraction of the initial ozone perturbation that remains at different potential temperatures as a function of time. This fraction is calculated as:

$f=100 \cdot \frac{\left(\frac{\mathrm{O}_{3}{ }^{p}-\mathrm{O}_{3}}{\mathrm{O}_{3}}\right)}{p}$

where $f$ is the remaining signal, $\mathrm{O}_{3}$ is the ozone concentration in the reference run, $\mathrm{O}_{3}^{p}$ the ozone concentration in the perturbation run and $p$ the initial perturbation (i.e. $30 \%$ ).

Figure 2 shows the value of $f$ averaged over the area north of $65^{\circ} \mathrm{N}$ equivalent latitude. The signal is completely lost after 2 months at $750 \mathrm{~K}$ and remains at values close to $100 \%$ in the lower stratosphere. Between these layers the signal remains present to variable degrees until early winter, when chemistry becomes so slow, that the remaining signal is preserved.

Figure 3 shows the evolution of $f$ on the potential temperature levels $450 \mathrm{~K}, 575 \mathrm{~K}$ and $750 \mathrm{~K}$ through autumn (September to December). While at $450 \mathrm{~K}$ most of the signal is still present in early January, the initial perturbation has been almost completely removed at $750 \mathrm{~K}$ at this time. At $575 \mathrm{~K}$ about $30 \%$ of the initial perturbation is still present.

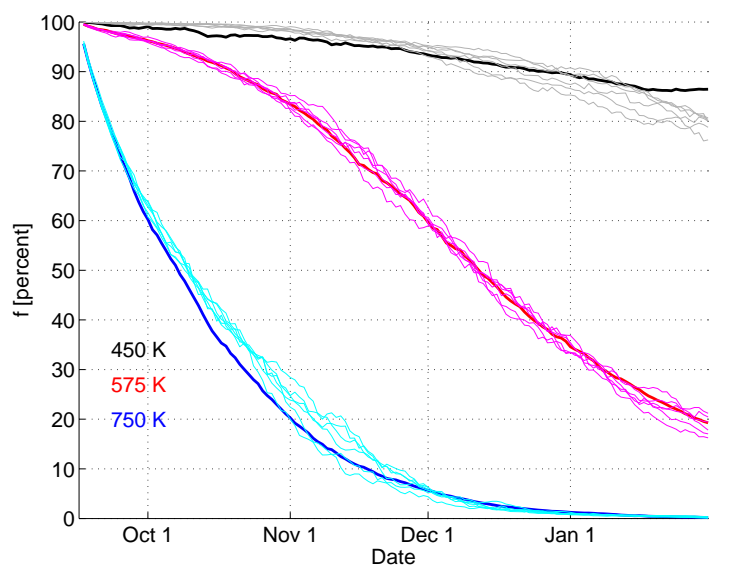

Fig. 3. Temporal evolution of the surviving fraction of an artificial ozone perturbation on 16 September 1999 at $450 \mathrm{~K}$ (thick black line), $575 \mathrm{~K}$ (thick red) and $750 \mathrm{~K}$ (thick blue), averaged over equivalent latitudes greater than $65^{\circ} \mathrm{N}$. Note that the lines do not show the same air mass at different dates. Air masses shown at later dates will have experienced more subsidence. Thin lines show results for additional runs at reduced resolution for the years 2005/2006 to 2010/2011.

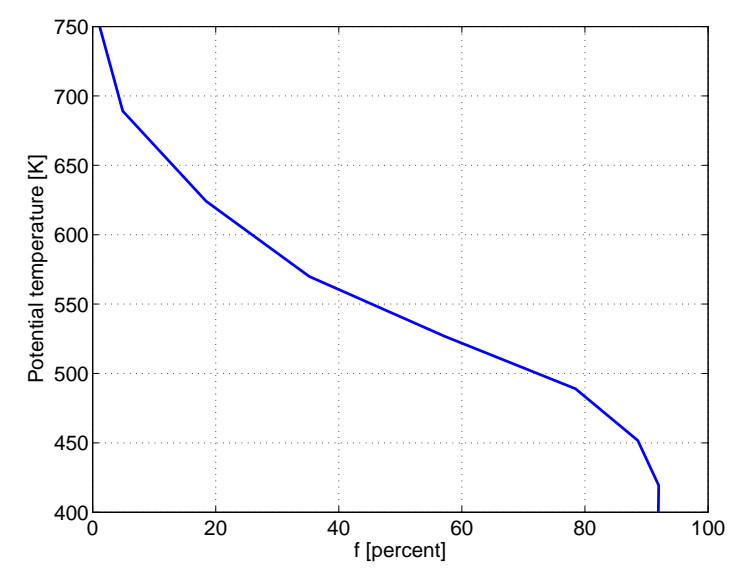

Fig. 4. Vertical profile of surviving fraction of an artificial ozone perturbation on 16 September 1999 on 3 January 2000, averaged over equivalent latitudes greater than $65^{\circ} \mathrm{N}$.

Note that the lines do not show the same air mass at different dates. Air masses shown at later dates will have experienced more subsidence. Since these air masses originate from higher altitudes, one of the reasons for the larger loss of signal later in time is the shorter chemical lifetime in higher altitudes (in addition to the decay of the signal in the same air mass).

The vertical profile of $f$ on 3 January is shown in Fig. 4. At $750 \mathrm{~K}$ the initial perturbation has essentially been removed from the system. Towards the lower stratosphere the signal rises to a maximum of around $90 \%$ at $400 \mathrm{~K}$.

It is clearly visible that ozone mixing ratios in the lower stratosphere are more sensitive to variability induced by 


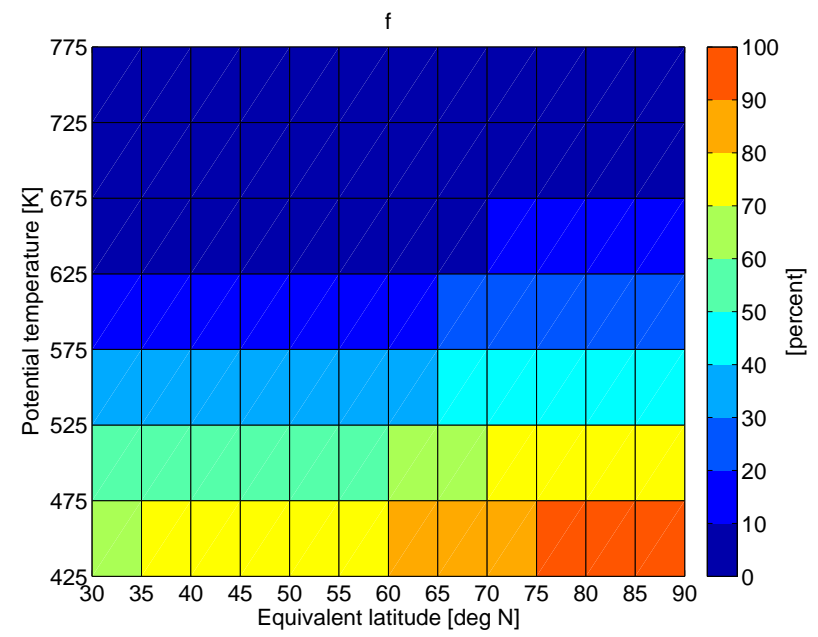

Fig. 5. Surviving fraction of an artificial ozone perturbation on 16 September 1999 as a function of equivalent latitude and potential temperature on 3 January 2000.

transport and mixing than in higher altitudes, as expected from the variation of the chemical lifetime of ozone with altitude.

Note that these results refer to a perturbation induced on 16 September. Perturbations induced at later dates will have a greater chance to survive until early winter. Variability in ozone mixing ratios in late autumn is observed at least up to $800 \mathrm{~K}$ (Kawa et al., 2003). If this variability in high altitudes is caused by dynamical differences (and not e.g. by differences in $\mathrm{NO}_{\mathrm{x}}$ ), it will be caused by relatively recent dynamical events.

Due to the variation of ozone lifetime with latitude, $f$ is not only a function of potential temperature but also of equivalent latitude. Figure 5 shows the variation of $f$ as function of potential temperature and equivalent latitude on 3 January 2000. The ozone field is binned and averaged into 5 degree equivalent latitude bins and $50 \mathrm{~K}$ potential temperature bins in the figure. At higher equivalent latitudes a larger fraction of the ozone variability, which is generated dynamically during the formation of the polar vortex in autumn, is preserved until the beginning of January. This is a consequence of the isolation of the polar vortex from lower latitudes in combination with the longer chemical lifetime of ozone at higher latitudes (Kawa et al., 2003).

The results are determined by the photochemical lifetime of ozone, which is a strong function of altitude, latitude and season. Since the solar insolation is the same in every year, we expect similar results in other years. Nevertheless, there are some factors leading to interannual variability in lifetimes. These are the interannual variability in $\mathrm{NO}_{\mathrm{x}}$ abundances, temperatures, transport and mixing, respectively. Additional $\mathrm{NO}_{\mathrm{x}}$ will decrease the lifetime and equilibrium value of ozone through the catalytic $\mathrm{NO}_{\mathrm{x}}$ cycle. Increased temperature will also decrease the lifetime of ozone due to the temperature dependency of the involved reactions. Different transport can lead to different solar zenith angle histories for air parcels. We have performed additional model runs to estimate the interannual variability in $f$ due to interannual variability in these parameters.

Runs were started with a reduced effective resolution of about $500 \mathrm{~km}$ for the years 2005/2006 to 2010/2011 and were driven by ERA Interim data of the respective years. $\mathrm{H}_{2} \mathrm{O}, \mathrm{HCl}, \mathrm{O}_{3}$ and $\mathrm{HNO}_{3}$ were initialized from measurements of the MLS instrument (Waters et al., 2006) on $1 \mathrm{Au}-$ gust of the years 2005-2010. $\mathrm{NO}_{\mathrm{x}}$ was initialized in two steps: First, $\mathrm{NO}_{\mathrm{x}} / \mathrm{HNO}_{3}$ was derived as a function of potential temperature and latitude from the $\mathrm{NO}_{\mathrm{x}}$ and $\mathrm{HNO}_{3}$ initialization of the reference run. Then, $\mathrm{NO}_{\mathrm{x}}$ was calculated from the $\mathrm{NO}_{\mathrm{x}} / \mathrm{HNO}_{3}$ relationship and the $\mathrm{HNO}_{3}$ initialization of the sensitivity run. This makes sure that $\mathrm{NO}_{\mathrm{x}}$ changes proportionally to $\mathrm{HNO}_{3}$ in the different years. For the rest of the species, the initialization of the original $200 \mathrm{~km}$ run was used. All changes were done for both the perturbed runs and the unperturbed runs. Figure 3 shows the temporal evolution of the surviving fraction of the ozone perturbation for the additional runs as thin lines. The differences between the runs stay below $10 \%$ at all three potential temperature levels and at any time.

\section{Conclusions}

The formation phase of the Arctic vortex in autumn (September to December) is an interesting period for chemistry, transport and mixing due to the ability of planetary waves to propagate deeply into the stratosphere and the still readily available solar radiation. Variability induced by transport and mixing during this period is damped by chemistry. The degree to which chemistry compensates for dynamically induced variability depends on the velocity of the chemical loss of ozone until polar night conditions suppress further chemical conversion of ozone. We have used ATLAS, a Lagrangian CTM, to study transport and chemistry during this phase and have quantified which fraction of dynamically induced variability in ozone survives chemical processing until early winter (begin of January), when ozone becomes a long lived species. Only in regions where the chemical lifetimes are long dynamical variability in autumn can influence the conditions in the polar vortex in the early winter season.

An ozone anomaly introduced artificially in early autumn was used to simulate the effect of interannual variability in ozone mixing ratios due to interannual differences in dynamics at this time. We found that an ozone anomaly induced during the polar vortex formation phase on 16 September 1999 can have a strong impact on early winter ozone mixing ratios inside the polar vortex up to about $600 \mathrm{~K}$. About $90 \%$ of the initial perturbation is still present at $400 \mathrm{~K}$ on 3 January, decreasing to $25 \%$ at $600 \mathrm{~K}$. A small impact is visible as high as $750 \mathrm{~K}$, where the chemical ozone loss reduces 
the initial ozone perturbation to $0.5 \%$ on 3 January. Above this level ozone concentrations essentially reach equilibrium at any time between the vortex formation and early winter, such that dynamically induced ozone anomalies are removed and the memory of ozone to transport and mixing processes during vortex formation is destroyed.

We found that these results were not sensitive to the magnitude of the initial perturbation. In addition, they were also not sensitive to the interannual variability in transport, mixing, $\mathrm{NO}_{\mathrm{x}}$ and temperatures in additional runs with a reduced resolution for the years 2005/2006 to 2010/2011.

These results highlight the importance of both chemical processing and the dynamical processes during the autumnal circulation reversal for ozone mixing ratios inside the early polar vortex.

Acknowledgements. We thank ECMWF for providing reanalysis data, K. Walker (U. Toronto) for providing ACE FTS data (The Atmospheric Chemistry Experiment (ACE) on the SCISAT satellite is a Canadian-led mission mainly supported by the Canadian Space Agency), the MLS science team at JPL, J.-U. Grooß and J. M. Russell III for providing HALOE data and ER-2 and Triple balloon tracer relationships. Work at AWI was partially supported by the EC project RECONCILE, Grant Agreement no. 236365.

Edited by: M. Dameris

\section{References}

Bernath, B. F., McElroy, C. T., Abrams, M. C., Boone, C. D., Butler, M., Camy-Peyret, C., Carleer, M., Clerbaux, C., Coheur, P.-F., Colin, R., DeCola, P., DeMazière, M., Drummond, J. R., Dufour, D., Evans, W. F. J., Fast, H., Fussen, D., Gilbert, K., Jennings, D. E., Llewellyn, E. J., Lowe, R. P., Mahieu, E., McConnell, J. C., McHugh, M., McLeod, S. D., Michaud, R., Midwinter, C., Nassar, R., Nichitiu, F., Nowlan, C., Rinsland, C. P., Rochon, Y. J., Rowlands, N., Semeniuk, K., Simon, P., Skelton, R., Sloan, J. J., Soucy, M.-A., Strong, K., Tremblay, P., Turnbull, D., Walker, K. A., Walkty, I., Wardle, D. A., Wehrle, V., Zander, R., and Zou, J.: Atmospheric Chemistry Experiment (ACE): Mission overview, Geophys. Res. Lett., 32, L15S01, doi:10.1029/2005GL022386, 2005.

Butchart, N. and Remsberg, E. E.: The area of the stratospheric polar vortex as a diagnostic for tracer transport on an isentropic surface, J. Atmos. Sci., 43, 1319-1339, 1986.

Carslaw, K. S., Luo, B., and Peter, T.: An analytical expression for the composition of aqueous $\mathrm{HNO}_{3}-\mathrm{H}_{2} \mathrm{SO}_{4}$ stratospheric aerosols including gas phase removal of $\mathrm{HNO}_{3}$, Geophys. Res. Lett., 22, 1877-1880, 1995.

Charney, J. G. and Drazin, P. G.: Propagation of planetary-scale disturbances from the lower into the upper atmosphere, J. Geophys. Res., 66, 83-109, 1961.

Dee, D. P., Uppala, S. M., Simmons, A. J., Berrisford, P., Poli, P., Kobayashi, S., Andrae, U., Balmaseda, M. A., Balsamo, G., Bauer, P., Bechtold, P., Beljaars, A. C. M., van de Berg, L., Bidlot, J., Bormann, N., Delsol, C., Dragani, R., Fuentes, M., Geer, A. J., Haimberger, L., Healy, S. B., Hersbach, H., Hólm, E. V.,
Isaksen, L., Kållberg, P., Köhler, M., Matricardi, M., McNally, A. P., Monge-Sanz, B. M., Morcrette, J.-J., Park, B.-K., Peubey, C., de Rosnay, P., Tavolato, C., Thépaut, J.-N., and Vitart, F.: The ERA-Interim reanalysis: configuration and performance of the data assimilation system, Q. J. Roy. Meteor. Soc., 137, 553-597, 2011.

Dorf, M., Butz, A., Camy-Peyret, C., Chipperfield, M. P., Kritten, L., and Pfeilsticker, K.: Bromine in the tropical troposphere and stratosphere as derived from balloon-borne $\mathrm{BrO}$ observations, Atmos. Chem. Phys., 8, 7265-7271, doi:10.5194/acp-8-72652008, 2008.

Fahey, D. W. and Ravishankara, A. R.: Summer in the stratosphere, Science, 285, 208-210, 1999.

Fahey, D. W., Gao, R. S., Del Negro, L. A., Keim, E. R., Kawa, S. R., Salawitch, R. J., Wennberg, P. O., Hanisco, T. F., Lanzendorf, E. J., Perkins, K. K., Lloyd, S. A., Swartz, W. H., Proffitt, M. H., Margitan, J. J., Wilson, J. C., Stimpfle, R. M., Cohen, R. C., McElroy, C. T., Webster, C. R., Loewenstein, M., Elkins, J. W., and Bui, T. P.: Ozone destruction and production rates between spring and autumn in the Arctic stratosphere, Geophys. Res. Lett., 27, 2605-2608, doi:10.1029/2000GL011404, 2000.

Farman, J., Murgatroyd, R. J., Silnickas, A. M., and Thrush, B. A.: Ozone photochemistry in the Antarctic stratosphere in summer, Q. J. R. Meteor. Soc., 111, 1013-1025, 1985.

Fioletov, V. E. and Shepherd, T. G.: Seasonal persistence of midlatitude total ozone anomalies, Geophys. Res. Lett., 30, doi:10.1029/2002GL016739, 2003.

Grooß, J.-U. and Russell III, J. M.: Technical note: A stratospheric climatology for $\mathrm{O}_{3}, \mathrm{H}_{2} \mathrm{O}, \mathrm{CH}_{4}, \mathrm{NO}_{\mathrm{x}}, \mathrm{HCl}$ and $\mathrm{HF}$ derived from HALOE measurements, Atmos. Chem. Phys., 5, 2797-2807, doi:10.5194/acp-5-2797-2005, 2005.

Grooß, J.-U., Günther, G., Konopka, P., Müller, R., McKenna, D. S., Stroh, F., Vogel, B., Engel, A., Müller, M., Hoppel, K., Bevilacqua, R., Richard, E., Webster, C. R., Elkins, J. W., Hurst, D. F., Romashkin, P. A., and Baumgardner, D. G.: Simulation of ozone depletion in spring 2000 with the Chemical Lagrangian Model of the Stratosphere (CLaMS), J. Geophys. Res., 107, 8295, doi:10.1029/2001JD000456, 2002.

Kawa, S. R., Bevilacqua, R. M., Margitan, J. J., Douglass, A. R., Schoeberl, M. R., Hoppel, K. W., and Sen, B.: Interaction between dynamics and chemistry of ozone in the setup phase of the Northern Hemisphere polar vortex, J. Geophys. Res., 108, 8310, doi:10.1029/2001JD001527, 2003.

Kawa, S. R., Newman, P. A., Stolarski, R. S., and Bevilacqua, R. M.: Fall vortex ozone as a predictor of springtime total ozone at high northern latitudes, Atmos. Chem. Phys., 5, 1655-1663, doi:10.5194/acp-5-1655-2005, 2005.

Kiesewetter, G., Sinnhuber, B.-M., Vountas, M., Weber, M., and Burrows, J. P.: A long-term stratospheric ozone data set from assimilation of satellite observations: Highlatitude ozone anomalies, J. Geophys. Res., 115, D10307, doi:10.1029/2009JD013362, 2010.

Rosenfield, J. E. and Schoeberl, M. R.: On the origin of polar vortex air, J. Geophys. Res., 106, 33485-33497, 2001.

Sander, S. P., Friedl, R. R., Ravishankara, A. R., Golden, D. M., Kolb, C. E., Kurylo, M. J., Molina, M. J., Moortgat, G. K., Finlayson-Pitts, B. J., Wine, P. H., Huie, R. E., and Orkin, V. L.: Chemical kinetics and photochemical data for use in atmospheric studies, Evaluation Number 15, JPL Publication 06-2, Jet Propul- 
sion Laboratory, California Institute of Technology, Pasadena, CA, USA, http://jpldataeval.jpl.nasa.gov, 2006.

Sander, S. P., Friedl, R. R., Abatt, J., Barker, J. R., Burkholder, J. B., Golden, D. M., Kolb, C. E., Kurylo, M. J., Moortgat, G. K., Wine, P. H., Huie, R. E., and Orkin, V. L.: Chemical kinetics and photochemical data for use in atmospheric studies, Evaluation Number 16, JPL Publication 09-31, Jet Propulsion Laboratory, California Institute of Technology, Pasadena, CA, USA, http://jpldataeval.jpl.nasa.gov, 2009.

Schoeberl, M. R. and Hartmann, D. L.: The dynamics of the stratospheric polar vortex and its relation to springtime ozone depletions, Science, 251, 46-52, 1991.

Sinnhuber, B.-M., von der Gathen, P., Sinnhuber, M., Rex, M., König-Langlo, G., and Oltmans, S. J.: Large decadal scale changes of polar ozone suggest solar influence, Atmos. Chem. Phys., 6, 1835-1841, doi:10.5194/acp-6-1835-2006, 2006.

Tilmes, S., Müller, R., Grooß, J.-U., Nakajima, H., and Sasano, Y.: Development of tracer relations and chemical ozone loss during the setup phase of the polar vortex, J. Geophys. Res., 111, D24S90, doi:10.1029/2005JD006726, 2006.

Waters, J. W., Froidevaux, L., Harwood, R. S., Jarnot, R. F., Pickett, H. M., Read, W. G., Siegel, P. H., Coeld, R. E., Filipiak, M. J., Flower, D. A., Holden, J. R., Lau, G. K., Livesey, N. J., Manney, G. L., Pumphrey, H. C., Santee, M. L., Wu, D. L., Cuddy, D. T., Lay, R. R., Loo, M. S., Perun, V. S., Schwartz, M. J., Stek, P. C., Thurstans, R. P., Chandra, K. M., Chavez, M. C., Chen, G.-S., Boyles, M. A., Chudasama, B. V., Dodge, R., Fuller, R. A., Girard, M. A., Jiang, J. H., Jiang, Y., Knosp, B. W., LaBelle, R. C., Lam, J. C., Lee, K. A., Miller, D., Oswald, J. E., Patel, N. C., Pukala, D. M., Quintero, O., Scaff, D. M., Snyder, W. V., Tope, M. C., Wagner, P. A., and Walch, M. J.: The Earth Observing System Microwave Limb Sounder (EOS MLS) on the Aura satellite, IEEE Trans. Geosci. Remote Sens., 44, 1075-1092, 2006.
WMO: World Meteorological Organization (WMO)/United Nations Environment Programme (UNEP), Scientific assessment of ozone depletion: 2010, Global Ozone Research and Monitoring Project - Report No. 52, 2011.

Wohltmann, I. and Rex, M.: The Lagrangian chemistry and transport model ATLAS: validation of advective transport and mixing, Geosci. Model Dev., 2, 153-173, 2009.

Wohltmann, I., Lehmann, R., and Rex, M.: The Lagrangian chemistry and transport model ATLAS: simulation and validation of stratospheric chemistry and ozone loss in the winter 1999/2000, Geosci. Model Dev., 3, 585-601, 2010. 